\title{
Nonoperative Management of Blunt Renal Trauma
}

\author{
${ }^{1}$ Aparecida Andrade Ribeiro Franciscani, ${ }^{2}$ Camila Issa Azevedo, ${ }^{3}$ Amanda Baraldi Souza \\ ${ }^{4}$ Maria Helena Almeida Costa, ${ }^{5}$ Sizenando Vieira Starling, ${ }^{6}$ Domingos André Fernandes Drumond
}

\begin{abstract}
Objective: To analyze patients with blunt renal trauma who were managed conservatively, with emphasis on clinical presentation, grade of injury, complication and failure rates.
\end{abstract}

Materials and methods: A prospective observational study was conducted in Hospital João XXIII, between January and December 2013. Patients with blunt renal trauma and nonoperative management (NOM) were analyzed during this period. Data were collected in respect to: age, gender, mechanism of trauma, grade of injury, clinical presentation, revised trauma score (RTS), associated abdominal injuries, length of hospital stay and failure, complication and mortality rates.

Results: During this period, 27 patients with blunt renal trauma were suitable for nonoperative approach. The most common mechanisms of trauma were motor vehicle accidents $(59.2 \%)$ and falls $(22.2 \%)$ and the mean length of hospital stay was 10.5 days. The majority of the patients had grade II (48.1\%) and III (29.6\%) injuries, with mean RTS of 6.93 . The complication rate was $3.7 \%$ and the mortality rate was $7.4 \%$. All deaths were related to associated injuries. One patient with grade II injury required nephrectomy. This patient had concurrent injuries.

Conclusion: Blunt renal trauma can be successfully managed conservatively, with low complication rates. Nonoperative management is safe in stable patients and in environments with appropriated protocol for this approach.

Keywords: Kidney, Blunt injuries, Renal trauma, Nonoperative.

How to cite this article: Franciscani AAR, Azevedo $\mathrm{Cl}$, Souza AB, Costa MHA, Starling SV, Drumond DAF. Nonoperative Management of Blunt Renal Trauma. Panam J Trauma Crit Care Emerg Surg 2015;4(1):6-10.

Source of support: Nil

Conflict of interest: None

\section{RESUMEN}

Objetivo: Analizar pacientes con trauma renal contundido sometidos a tratamiento no operatorio (TNO), con énfasis en los datos clínicos a la admisión, grado de la lesión e índices de complicación y falla de ese tipo de tratamiento.

\footnotetext{
${ }^{1-5}$ Trauma Surgeon, ${ }^{6}$ Chief Surgeon

${ }^{1-6}$ Department of General and Trauma Surgery, Hospital João XXIII, Minas Gerais, Brazil
}

Corresponding Author: Aparecida Andrade Ribeiro Franciscani, Trauma Surgeon, Department of General and Trauma Surgery, Hospital João XXIII, Minas Gerais, Brazil Phone: 553132399200, e-mail: afranciscani@yahoo.com.br
Materiales y métodos: Estudio prospectivo de casos de trauma renal contundido admitidos en el Hospital João XXIII de enero a diciembre de 2013 sometidos a tratamiento no operatorio (TNO). Las variables analizadas fueron edad, sexo, mecanismo de trauma, grado de la lesión, parámetros clínicos a la admisión, índice de trauma - Revised Trauma Score (RTS), lesiones abdominales asociadas, tiempo de hospitalización, índice de falla del tratamiento, tasas de complicación y mortalidad.

Resultados: En ese período, 27 pacientes con trauma renal contundido cumplieron criterios para tratamiento no operatorio (TNO). Los principales mecanismos de trauma fueron los accidentes con vehículos automotores $(59.2 \%)$ y caídas (22.2\%) y el tiempo promedio de hospitalización fue 10.5 días (2-29). La mayoría de los pacientes presentaron lesiones grados II (48.1\%) y III (29.6\%), con RST promedio de 6.93. EI índice de complicación fue de $3.7 \%$ y la tasa de mortalidad fue de $7,4 \%$, siendo $100 \%$ de los óbitos relacionados a otras causas. Hubo falla del TNO en un paciente $(3.7 \%)$ con lesión renal grado II y con otras lesiones abdominales asociadas.

Conclusiónes: El tratamiento no operatorio en el trauma renal contundido presenta alto índice de éxito y baja tasa de complicación. Es seguro en pacientes seleccionados, dentro del hospital con protocolo apropiado para ese tipo de tratamiento.

Palabras claves: Riñon, Trauma contundido, Trauma renal, No operatorio.

\section{INTRODUCTION}

The kidneys are located in the retroperitoneal space, enclosed by Gerota's fascia. Because of this protected position, it is one of the less injured solid organs in trauma. Renal injuries occur in approximately 1 to $3 \%$ of all trauma patients and in $10 \%$ of abdominal trauma. ${ }^{1-3}$

The last three decades were remarkable for the improvements in nonoperative management (NOM) of solid organs injuries.

The advances in technology of images and the widespread availability of computed tomography (CT) scan was of great importance for the increasing in conservative approach. ${ }^{4,5}$

Nowadays, NOM is the standard of care for stable patients with blunt renal trauma. ${ }^{1,3,4,6,7}$ Besides having high success rate, it has lower costs and lower hospital length of stay (LOS) if compared to surgical approach.

Despite of the countless advantages of NOM, it is not always feasible. Some aspects are essential for this approach, such as properstructureand anappropriated protocol as well as a trained team for this kind of management.

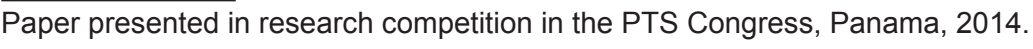




\section{MATERIALS AND METHODS}

This is an observational prospective study conducted in Hospital João XXIII, a Trauma Center situated in Belo Horizonte, Brazil, which estimated population is ${ }^{5,7}$ million people.

From January to December 2013, there were 27 patients with blunt renal trauma admitted in Hospital João XXIII who met the criteria for NOM.

According to our Institution's protocol, hemodynamic stability at admission or after resuscitation and absence of peritonitis are mandatory to NOM. Additionally, all renal injuries are graded based on CT scan findings and according to the American Association for the Surgery of Trauma (AAST).

Failure of conservative management was defined as necessity of surgery at any time after the decision to NOM has been made.

All patients were followed during 8 weeks postinjury. Follow-up images were done in cases of injuries grades IV and V in order to evaluate injury healing and kidney function, postdischarge.

Data were collected in respect to: age, gender, mechanism of trauma, grade of injury, clinical presentation, revised trauma score (RTS), associated abdominal injuries, LOS and failure, complication and mortality rates.

\section{RESULTS}

During this period, 27 patients with blunt renal trauma have been selected for NOM. The majority of them were men $(81.5 \%)$ aging between 20 and 35 years. Patients younger than 20 years and older than 35 years represented 33.3 and $7.4 \%$ respectively.

The most common mechanism of trauma was motor vehicle accidents, with $59.2 \%$. Falls were the second cause of injury, accounting for $22.2 \%$.

The grades of renal injury included grade I in 2 patients, grade II in 13, grade III in 8 , and grade IV in 4 patients (Graph 1).

Concerning hospitalization, the mean LOS was 10.5 days, ranging from 2 to 29 days. The majority of the patients were discharged in the first week, while $29.6 \%$ stayed at the hospital between 8 and 14 days, and 22.2\% were hospitalized for more than 14 days.

There was no relation between severity of injury and LOS stay. All patients with grade I injury stayed in the hospital more than 14 days, whereas $61.5 \%$ of the ones with grade II and half of the ones with grade III injury were discharged in the first week. Among patients with grade IV, 2 (50\%) of them stayed between 8 and 14 days in hospital. It probably occurred because all patients with

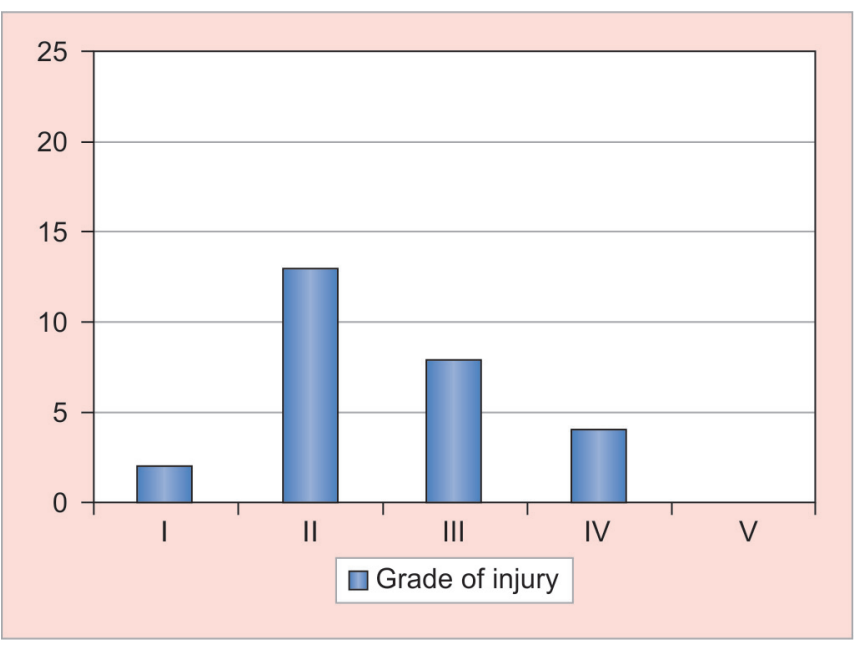

Graph 1: Classification of renal injury by grade

low-grade renal injury had associated injuries that were responsible for the prolonged hospitalization.

Of 27 patients, 21 (77.8\%) had abdominal associated injuries. Among them, $9(42.8 \%)$ had splenic injury and $9(42.8 \%)$ had liver injury. Three patients had both splenic and liver injury (Graph 2).

The RTS could be calculated in 24 (88.9\%) patients. The mean RTS was 6.93 , ranging from 4.09 to 7.84 .

The complication rate was low: one patient underwent arteriography and embolization because of bleeding. There was failure of conservative management in 1 (3.7\%) patient with grade II injury, who required nephrectomy because of bleeding and hemodynamic instability. There were no deaths related to renal injury. All of them $(7.4 \%$ of 27 patients) were caused by severe traumatic brain injury.

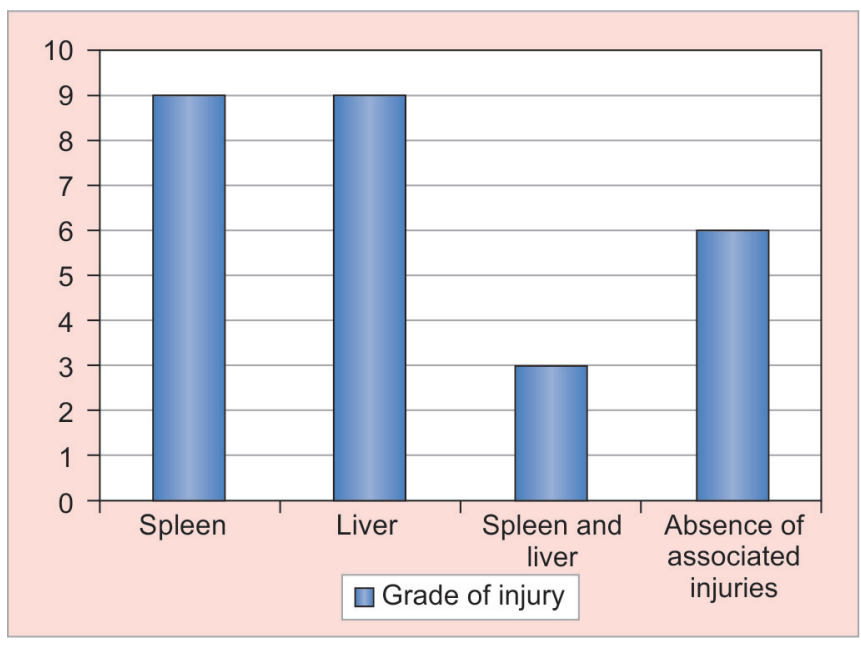

Graph 2: Associated abdominal injuries

\section{DISCUSSION}

Blunt trauma comprises 90 to $95 \%$ of all renal injuries, and the most common mechanisms of injury are motor vehicle accidents, falls and sports. $3,5,8$

According to literature, the majority of blunt renal injuries are low and moderate grade injuries. ${ }^{1,8}$ In our 
study, $48.1 \%$ had grade II injury and grade III accounted for $29.6 \%$. A retrospective study of Aragona et al showed that $80 \%$ of 1460 patients had grade I and II injuries. ${ }^{5}$

In a study with 338 patients, Shoobridge et al found a mean LOS of 10.7 days, which is very similar to ours: 10.5 days. ${ }^{1}$ There was no relation between LOS and severity of injury in both studies.

The current study reported a high rate of associated abdominal injuries in blunt renal trauma, which is consistent to the literature. ${ }^{1,4}$ Of a total of 27 patients, $77.8 \%$ had other solid organ injuries, and there was no difference between rates of splenic and liver injuries.

Santucci et al, in a systematic review of renal trauma, demonstrated a significant variation in complication rate between the series revised, ranging from 0 to $34 \%$, with a mean of $10 \% .^{9}$ It can be explained by the fact that the majority of the studies are retrospective and comprises a small number of patients. Another important bias is the lack of standardization in some definitions. For example, post injury time when hematuria is considered persistent. In our study, complication occurred in 1 patient (3.7\%), which required arteriography and embolization because of bleeding. No patients developed urinoma or infected hematoma. Wilden et al, in a multicenter study conducted in England, comprising 206 patients with grade IV and V injuries, found a complication rate of $31.8 \% .{ }^{2}$ Persistent hematuria was the most common complication, accounting for $16.2 \%$, followed by urinoma, present in $10.2 \%$ of the patients. Other complications documented in the literature are arteriovenous fistula, pseudoaneurysm, hypertension and delayed bleeding., ${ }^{9,10}$

Success rate is high in blunt renal trauma even in high-grade injuries. ${ }^{2,7} 8$ According to Prasad et al, the main predictors of failure in NOM are grade V injury and necessity of massive blood transfusion. ${ }^{8}$

\section{CONCLUSION}

The advantages of NOM in blunt renal trauma are countless. As demonstrated in the present study, even complex injuries, comprising collector system, can be managed conservatively.

In our hospital, NOM is considered for all patients with blunt renal trauma who met our protocol criteria.

Finally, in our experience, following a specific protocol is of great importance to the successful management of these injuries.

\section{REFERENCES}

1. Shoobridge JJ, Bultitude MF, Koukounaras J, Martin KE, Royce PL, Corcoran NM. A 9-year experience of renal injury at an Australia level 1 trauma centre. BJU Int 2013;112(Suppl 2): 53-60.

2. Wilden GM, et al. Successful nonoperative management of the most severe blunt renal injuries-a multicenter study of the research consortium of New England centers for trauma. JAMA Surg 2013;148(10):924-931.

3. Vlies CH, Delden OM, Ponsen KJ, Rosette JJMCH, Reijke TM, Goslings JC. Management of blunt renal injury in a level 1 trauma centre in view of European guidelines. Int J Care Injured 2012;43(11):1816-1820.

4. McCombie SP, Thyer I, Corcoran NM, Rowling C, Dyer J, Le Roux A, Kuan M, Wallace DMA, Hayne D. The conservative management of renal trauma: a literature review and practical clinical guideline from Australia and New Zealand. BJU Int 2014;114(Suppl 1):13-21.

5. Aragona F, Pepe P, Patanè D, Malfa P, D'Arrigo L, Pennisi M. Management of severe blunt renal trauma in adults patients: a 10-year retrospective review from an emergency hospital. BJU Int 2012;110(8):744-748.

6. Broghammer JA, Fisher MB, Santucci RA. Conservative management of renal trauma: a review. Urology 2007;70(4): 623-629.

7. Starnes M, Demetriades D, Hadjizacharia P, Inaba K, Best C, Chan L. Complications following renal trauma. Arch Surg 2010;145(4):377-381.

8. Prasad NH, Devraj R, Chandriah GR, Sagar SV, Reddy CR, Murthy PVLN. Predictors of nephrectomy in high grade blunt renal trauma patients treated primarily with conservative intent. Indian J Urol 2014;30(2):158-160.

9. Santucci RA, Fisher MB. The literature increasingly supports expectante (conservative) management of renal trauma-A systematic review. J Trauma 2005;59(2):493-503.

10. Silva LF, Teixeira LC, Rezende Neto JB. Abordagem do trauma renal—artigo de revisão. Rev Col Bras Cir 2009;36(6): 519-524. 


\section{INVITED COMMENTARY}

\section{Nonoperative Management of Blunt Renal Trauma}

I would like to congratulate Franciscani et al on their prospective cohort study of 27 patients presenting with blunt renal trauma, all treated nonoperatively. This is an excellent study that has highlighted several points about renal trauma and nonoperative management. The first point the authors demonstrate is that is it indeed very difficult to find patients with isolated renal trauma after blunt injury. In their cohort, $78 \%$ of patients have associated intraabdominal injuries, making it challenging to draw specific conclusions about the management of blunt renal trauma in particular. Close to half of their patients presented with concomitant liver and/or splenic injuries, also treated nonoperatively, none requiring laparotomy for splenectomy or hepatorrhaphy. One wonders if the isolated patient with a grade II renal injury failed nonoperative management due to hemodynamic instability simply because of renal bleeding or because of hemorrhage from other organs, prompting the decision to operate. It is indeed difficult to find patients with isolated blunt renal trauma, thus formulating specific therapy and management algorithms becomes a challenging endeavor.

Another excellent point demonstrated by the authors is that organ injury severity (OIS) did not predict either failure of nonoperative management or need for nephrectomy. This is in keeping with what we have been learning about the nonoperative management of other solid organ injuries. Hemodynamic status (itself in need of clear definition) is both an indicator and predictor of the need for operative or multimodality therapy, much more so than OIS. This paper reinforces this principle as even patients with high grade OIS were successful candidates of nonoperative management. Additionally interesting in this study, however, was that length of stay was also independent of OIS. This could be for several reasons. One reason could be that length of stay was due to severe, concomitant injuries in the setting of minor renal trauma. The second reason, however, could simply be due to surgeon behavior. Individual trauma surgeons may have their own subjective reasons and timelines for deciding on what the 'appropriate' length of stay may be after blunt renal trauma. Some may be erroneously guided by the presence (or absence) of gross hematuria. ${ }^{1}$ Length of stay is also closely related to the amount of time each patient was prescribed the old-fashioned approach of bed-rest for at least 1 week in solid organ injury, a practice that dates back to the 1960s in the pediatric literature. ${ }^{2}$ This outdated mode of patient therapy was unlikely to have occurred in this study as the majority of patients were discharged within the first week. This is in keeping with other forward thinking Latin American trauma centers, which have historically been the drivers of evidence in trauma for the rest of the world. It also speaks to the need for protocolized care, as mentioned by the authors to reduce variability in therapy. This has been demonstrated to lead to improvements in patient outcomes in other solid organ injuries and nonoperative management. ${ }^{3}$

Lastly, this review serves as an excellent reminder that multimodal therapy is an important tool to use in blunt renal trauma. This includes angioembolization for ongoing blood loss, (in absence of significant hemodynamic instability), or stenting of the genitourinary collecting systems to avoid significant complications in the long-term related to urinary leak. One patient in this Brazilian cohort required angioembolization, none required endourological intervention. It would be interesting to know if there were any significant long-term complications even beyond the author's 8-week mark. Did any kidneys demonstrate nonhealing on follow-up imaging? Were any late nephrectomies or delayed surgical interventions performed due to nonperfusion? These and other questions remain to be seen in future studies.

I commend the authors on their excellent study which reminds us that isolated renal injuries are rare in blunt trauma, that nonoperative (and at times multimodal) management may be applied, using a hospital-based protocol, regardless of grade of injury. Also, we have been reminded that clinical criteria should guide ultimate discharge home and return to normal activity. These findings indeed reinforce the results of the Eastern Association for the Surgery of Trauma's practice guidelines for this topic from $2004{ }^{4}$ 


\section{REFERENCES}

1. Fraser JD, Aguayo P, Ostlie DJ, St Peter SD. Review of the evidence on the management of blunt renal trauma in pediatric patients. Pediatr Surg Int 2009;25:125-132.

2. Tank ES, Eraklis AJ, Gross RE. Blunt abdominal trauma in infancy and childhood. J Trauma 1968;8:439-448.

3. Haan J, Ilahi ON, Kramer M, Scalea TM, Myers J. Protocol-driven nonoperative management in patients with blunt splenic trauma and minimal associated injury decreases length of stay. J Trauma 2003;55:317-321.

4. Available at: http://www.east.org/resources/treatment-guidelines/genitourinary-trauma-management-of.

Tanya Zakrison

Assistant Professor, Department of Surgery University of Miami, FI, United States 